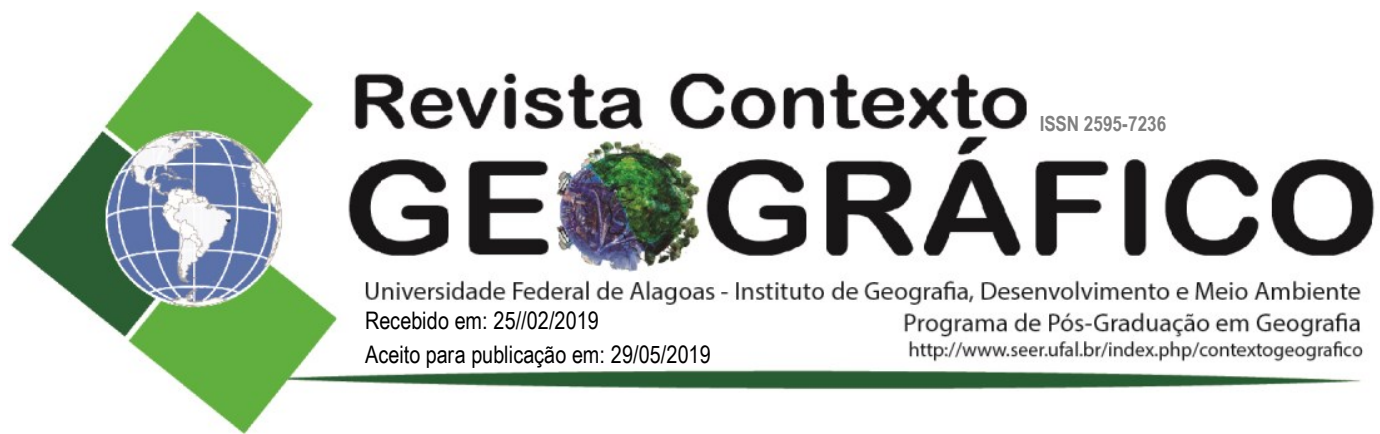

\title{
OS ALICERCES DA FORMAÇÃO ECONÔMICA NO NORDESTE BRASILEIRO: UMA ANÁLISE A PARTIR DA SUB-REGIÃO AGRESTE
}

\author{
Paul Clívilan Santos Firmino \\ Programa de Pós-Graduação em Geografia Humana do Departamento de Geografia da \\ Faculdade de Filosofia, Letras e Ciências Humanas - Universidade de São Paulo/USP \\ pcfirmino@usp.br
}

\begin{abstract}
RESUMO - O Nordeste apresenta cidades que foram se desenvolvendo e formando diversos centros regionais por todo o seu território, destacando cidades interioranas que são consideradas capitais regionais, tendo na feira livre evento que contribui para expansão do comércio, serviços e indústrias. Cidades como Itabaiana/SE, Caruaru/PE, Feira de Santana/BA e diversas outras, têm suas gêneses atreladas a este evento que é marca registrada no processo de desenvolvimento econômico, social e cultural. O presente artigo faz uma discussão em torno da gênese e formação da vida econômica nordestina, com especial atenção para a sub-região Agreste e o papel desempenhado pela feira livre. Destarte, o uso de um referencial teórico centrado no entendimento de variáveis como: região e sub-região, Agreste nordestino, feira livre, desenvolvimento econômico, dinamicidade e centralidade, a partir de autores como Andrade (1979), Santos ([1979] 2008), Melo (1980), Braudel (1998), Pazera Jr. (2003), Dantas (2007), Mamigonian (2009), Santos e Silveira (2010) entre outros, mostrou-se imprescindível nesta análise. Constatou-se um desenvolvimento centrado nas iniciativas locais e na feira livre, com surgimento de pequenos negócios com mão de obra local, capital próprio e técnicas não tão modernas, contribuindo para o nascimento de centros regionais que continuam dinamizando o Agreste e o interior Nordestino.
\end{abstract}

Palavras-chave: Feira Livre; Desenvolvimento Econômico e Regional; Cidades Agrestinas.

\section{THE STRUCTURE OF ECONOMIC FORMATION IN THE BRAZILIAN NORTHEAST: AN ANALYSIS FROM THE SUB-REGION AGRESTE}

\begin{abstract}
The Northeast presents cities that have been developing and forming several regional centers throughout its territory, including the cities of the interior that are considered regional capitals, being the street market event that contributed to the expansion of commerce, services and industries. Cities such as Itabaiana / SE, Caruaru / PE, Feira de Santana / BA and several others, have their genesis tied to this event that is registered mark in the process of economic, social and cultural development. This article makes a discussion about the genesis and formation of Northeastern economic life, with special attention to the Agreste sub-region and the role developing by street market. Therefore, the use of a theoretical reference centered on the understanding of variables such as: region and sub-region, Northeastern Agreste, street market, economic development, dynamicity and centrality, from authors like Andrade (1979), Santos ([1979] 2008 ), Melo (1980), Braudel (1998), Pazera Jr. (2003), Dantas (2007), Mamigonian (2009), Santos and Silveira (2010), and others, it was essential in this analysis. All things considered, it was found a development focused on local initiatives and the street market, with the emergence of small businesses with local work, own capital and not so modern techniques, contributing to the emergence of regional centers that continue to dynamize the Agreste and the interior Northeast.
\end{abstract}

Keywords: Street Market, Economic and Regional Development, Agrestinas Cities.

\section{INTRODUÇÃO}

O presente artigo tem como objetivo central fazer uma discussão em torno da gênese e formação da vida econômica nordestina, com especial atenção para a sub-região Agreste mediante o papel 
desempenhado pela feira livre. Para tanto, é essencial entender que a construção de uma vida de relações social e econômica está atrelada diretamente aos diversos períodos e eventos pelos quais o Nordeste brasileiro e suas respectivas sub-regiões passaram. Com isto, observa-se que "a cada momento histórico cada elemento muda seu papel e a sua posição no sistema temporal e no sistema espacial e, a cada momento, o valor de cada qual deve ser tomado da sua relação com os demais e com o todo" (SANTOS, [1985] 2008, p. 20).

Neste sentido, para contemplar o objetivo traçado foi essencial fazer uma discussão de algumas categorias-chave no entendimento da temática ora apresentada: feira livre, iniciativas locais, desenvolvimento econômico, sub-região, Agreste e Nordeste, baseando-se em autores como Rangel (1959), Santos ([1979] 2008), Araújo (1997), Andrade (1998), Braudel (1998), Diégues Jr. (2006), Dantas (2007), Santos (2008) entre outros. Vale ressaltar que foi essencial também uma investigação histórica e da realidade econômica que envolve algumas cidades agrestinas. Foram importantes nesta empreitada as informações e dados disponibilizados por órgãos como o Instituto Brasileiro de Geografia e Estatística/IBGE e o Ministério do Trabalho e Emprego/MTE.

A vida do povo nordestino foi marcada inicialmente pela cultura canavieira, sendo a base da vida social, cultural, política e econômica do Nordeste nos primeiros séculos de povoação. Começava a se formar um mercado que se baseava inicialmente num comércio de exportação, com a Metrópole portuguesa à frente, conforme aponta autores como Guimarães (1989) e Diégues Jr. (2006). O Nordeste foi durante um longo tempo a mais dinâmica e rica região do país, com os engenhos (contava com 230 engenhos em fins do século XVI - DIÉGUES JR., 2006) sustentando o sistema econômico brasileiro, com destaque para Pernambuco, de onde nasceu a sociedade brasileira, espalhando-se por todo o Nordeste, inicialmente, ao Norte por Paraíba, Rio Grande do Norte e até mesmo Ceará. Ao Sul pode-se citar Alagoas "pelo Rio São Francisco -, através de Sergipe e do Recôncavo Baiano. É que aí a sociedade em formação encontrou condições similares de existência, nascida igualmente da agricultura canavieira [...]" (DIÉGUES JR., 2012, p. 50).

Diversos eventos marcaram o processo de formação da região ao longo do tempo. No entanto, não será discutido aqui cada um dos eventos e os seus desdobramentos, mas fazer breves apontamentos acerca dos mesmos, sempre que necessário, torna-se essencial no entendimento da gênese e dinamicidade da região e, consequentemente, da sub-região Agreste. Sendo assim, entre idas e vindas ao desenvolvimento econômico e regional, dando um salto na história, já em meados do século $\mathrm{XX}$, mais uma vez o Nordeste passa a vir à tona nas discussões políticas e nos diversos estudos e debates envolvendo a economia brasileira.

Uma das formas de discutir a questão regional e buscar sanar os possíveis 'problemas' regionais, mediante investimentos do Governo Federal, foi a criação em fins da década de 1950 da Superintendência de Desenvolvimento do Nordeste/SUDENE. Contudo, não foi fácil, visto a resistência por parte da elite econômica, que por sua vez também era a elite política (açucareira e latifundiária).

Pode-se dizer que a década de 1960 foi um marco para a região, passando a expressar de forma mais intensa a capacidade da mesma de desenvolver-se além da canavicultura, apresentando um significativo aumento no comércio, serviços e no desenvolvimento de diversas empresas e indústrias regionais, que contribuíram para um melhor desempenho da região no que concerne a sua economia entre as décadas de 60-90. Isto mostra que:

\footnotetext{
A partir dos anos 60, impulsionadas por incentivos fiscais - 34/18-Finor e isenção do imposto sobre a renda, principalmente -, por investimentos de empresas estatais do porte da Petrobrás (na Bahia e Rio Grande do Norte) e da Vale do Rio Doce (no Maranhão), complementados com créditos públicos (do BNDES e BNB, particularmente) e com recursos próprios de importantes empresas locais, nacionais e multinacionais, as atividades urbanas - e dentro delas, as atividades industriais ganham crescentemente espaço no ambiente econômico do Nordeste e passam a comandar o crescimento da produção na região, rompendo a fraca dinâmica preexistente. (ARAÚJO, 1997, p. 8)
} 
Logo, a sociedade sustentada através dos sistemas de exploração da terra e de um conservadorismo doentio que vinha atravessando os séculos não é mais plausível e nem deve justificar a diversidade econômica encontrada no interior nordestino. Desta forma, as iniciativas empresariais locais e regionais fazem parte integrante da economia que vem se estruturando no Nordeste desde os últimos decênios do século passado, mas que tem raízes lá atrás, nos primeiros meios de trocas feitos quando houve a chegada dos portugueses em terras brasileiras e que hoje movimenta diversas cidades nordestinas, com especial destaque para as localizadas no Agreste, diga-se a feira livre, que traz, na atualidade, uma dinamicidade única para a presente sub-região, podendo ser vista mediante cidades como Caruaru/PE, Arapiraca/AL e Itabaiana/SE.

Assim, abordar as peculiaridades que envolvem o Agreste torna-se relevante para perceber o quanto nos dias atuais esta sub-região apresenta-se como uma das mais dinâmicas e com um comércio exuberante e uma intensificação das relações econômicas com cidades circunvizinhas, outros estados e regiões.

\section{APONTAMENTOS DA FORMAÇÃO ECONÔMICA E PARTICULARIDADES DO NORDESTE BRASILEIRO}

A sociedade brasileira e sua respectiva vida econômica possuem seus alicerces centrados principalmente na cana-de-açúcar e nos engenhos que passaram a ser implantados em diversas partes do território nacional, consolidando, junto com outros gêneros, a exemplo do algodão, coco, café etc., as bases econômicas, política e social da região Nordeste, sendo considerado "o primeiro centro econômico de produção, primeiro centro social, de formação da sociedade brasileira, primeiro centro de relações demográficas" (DIÉGUES JR., 2006, p. 9).

Nos dois primeiros séculos de colonização o Nordeste apresentou-se como a região de maior dinamismo econômico, com uma atividade e produção em torno da cultura canavieira voltada a então colônia portuguesa, dando prosseguimento à implantação de mais engenhos e, consequentemente, ocupando economicamente as terras brasileiras - com imposição de técnicas e capitais num meio tido como 'virgem' - a partir de um comércio europeu em expansão.

É sabido, conforme relatam alguns historiadores, que o comércio era o objetivo principal dos colonizadores, sendo a ocupação das terras brasileiras uma consequência deste comércio que se desenhava, impulsionando o capitalismo comercial que estava em desenvolvimento, sendo atribuído a este, de acordo com Andrade (1979, p. 13) "o descobrimento e a organização do território brasileiro, em geral, e do Nordeste em particular", ao tempo em que este capitalismo que estava sendo impulsionado, configurava-se como resultado "de uma circulação de mercadorias largamente desenvolvida, que ultrapassa os limites de um país. Um país capitalista sem comércio exterior é impensável - e, aliás, não existe" (LÊNIN, 1982, p. 30).

Pensar em todos os desdobramentos pelos quais o Nordeste passou ao longo destes mais de 500 anos de invasão portuguesa é refletir acerca dos problemas e das desigualdades regionais criadas mediante os avanços e consolidação do capitalismo. Com os avanços das desigualdades e as várias tentativas do Estado brasileiro para amenizar ou saná-las, os anos de 1950 foram um marco no que se refere às discussões mais aprofundadas a respeito da questão regional como forma de compreender e atuar sobre o território nacional. Dentre as tentativas de amenizar as diferenças e desequilíbrios regionais está a criação em 1959 da Sudene, tendo a frente desta o economista Celso Furtado. De acordo com a geógrafa Flávia Grimm,

\footnotetext{
Naquele momento, buscava-se resolver os graves problemas socioeconômicos do Nordeste brasileiro através de um programa voltado para a sua industrialização, incentivado por políticas tributárias. Esta grande região caracterizava-se ainda pela predominância de estruturas econômicas tradicionais, com a presença de latifúndios improdutivos (sobretudo no sertão) e de minifúndios, em grande parte incapazes de prover as necessidades de uma família devido a falta de apoio pelas instâncias governamentais. (GRIMM, 2011, p. 72)
} 
A Sudene apresentou novas maneiras de encarar os problemas presentes na região, seja no aspecto econômico, seja nas ações administrativas. Foi preciso encarar e combater diretamente à pobreza e à seca a partir de uma economia regional, não se atendo e beneficiando os interesses latifundiários do açúcar, nem mesmo seguir com planos imediatistas de socorro as vítimas das secas em épocas específicas.

Trilhando por este caminho pode-se afirmar que a década de 1950 foi emblemática para a ciência geográfica, estando esta, nas mais variadas discussões, apresentando a significativa importância que a região teve e tem para o todo nacional, contrapondo-se a ideias errôneas acerca de uma região problemática, mesmo convivendo dia a dia com dificuldades que atingem grande parte da população, reflexo de uma colonização bastante violenta e de uma 'herança maldita' deixada pelos colonizadores, atrelada aos ditames do período atual e seus principais atores hegemônicos da economia.

A utilização da enorme diversidade apresentada pela região é uma forma de coloca-la em evidência a nível nacional, ultrapassando obstáculos impostos outrora, dinamizando de forma mais ampla a região, garantindo maior desenvolvimento econômico e, consequentemente, tirando-a da marginalidade no que se refere aos investimentos (capitais e/ou mão de obra) que em sua maioria são concentrados "tanto no Centro-Sul, onde se estêve montando o arcabouço inicial do parque industrial brasileiro, quanto nas novas áreas que, como parte do esfôrço geral de desenvolvimento, estão surgindo continuamente nas zonas pouco ou não habitadas" (RANGEL, 1959, p. 419).

Então, pensando na região Nordeste, nota-se que não é fácil ter grandes mudanças em curtos períodos de tempos, visto que, os representantes políticos buscam apenas sanar dificuldades imediatistas, não se preocupando com problemas estruturais que afetam a região há séculos. Desta forma, os governantes sempre buscam transformações que estejam diretamente relacionadas com seus próprios benefícios e os interesses dos latifundiários, já que, as oligarquias nordestinas, em sua maioria, são formadas por políticos que representam a região. Diante disto, Andrade (1984, p. 31) aponta que,

O sistema imposto por uma minoria - as classes dominantes - sobre uma maioria dominada elabora uma série de padrões sociais que corresponde aos seus interesses e aspirações, e se utiliza dos aparelhos do Estado para fazer a atividade de repressão e de legitimação dos ideais elaborados.

Sabendo-se que o processo de formação da região faz parte de um conjunto de mudanças pelas quais o Nordeste tem passado nos diversos períodos de sua história, cabe aqui mostrar que as significativas mudanças que vem ocorrendo na região nas últimas décadas, conduzindo a superar os 'problemas' ainda existentes, contribuindo para um maior desenvolvimento regional, devem-se em parte ao dinamismo apresentado por diversas cidades interioranas, principalmente, as localizadas no Agreste, possibilitando um uso mais diversificado da terra, criação de micro e pequenas empresas, proporcionando maior diversificação nas atividades existentes.

Seguindo por esta linha de raciocínio, pode-se dizer que os estímulos à industrialização foi outro ponto chave para a modernização da estruturação econômica e um maior dinamismo das atividades presentes na região. Este dinamismo foi na contramão dos discursos arcaicos de uma região com baixo poder de desenvolvimento econômico, mostrando que não se deve pensar no Nordeste e sua respectiva economia apenas considerando a atividade do setor primário-exportador, mas sim, sendo preciso considerar a diversidade dos setores econômicos, como é possível verificar, mediante as ideias de Araújo (1997, p. 8) entre os anos de 1967 e 1989, assim como através da Tabela 01. Região Nordeste: evolução dos estabelecimentos com vínculos (1995-2013).

Entre 1967 e 1989 a agropecuária reduziu sua contribuição ao PIB regional de 27,4\% para $18,9 \%$ e em 1990 , ano de seca, que afetou consideravelmente a produção na zona semi-árida, tal percentual caiu para $12,1 \%$. Enquanto isso, a indústria passou de 22,6\% para $29,3 \%$, e o setor terciário cresceu de $49,9 \%$ para $58,6 \%$, segundo dados da Sudene para o período. 
Tabela 1. Região Nordeste: evolução dos estabelecimentos com vínculos (1995-2013)

\begin{tabular}{l|c|c|c|c|c}
\hline \multicolumn{1}{c|}{ Subsetor } & \multicolumn{5}{c}{ Ano } \\
\cline { 2 - 6 } & $\mathbf{1 9 9 5}$ & $\mathbf{2 0 0 0}$ & $\mathbf{2 0 0 5}$ & $\mathbf{2 0 1 0}$ & $\mathbf{2 0 1 3}$ \\
\hline Indústrias** & 6.791 & 9.609 & 12.512 & 17.799 & 21.109 \\
Instituição Financeira & 4.027 & 4.502 & 5.056 & 6.374 & 7.624 \\
Ensino & 5.225 & 7.645 & 8.983 & 11.614 & 13.790 \\
Administração Pública & 2.752 & 3.619 & 4.181 & 4.619 & 4.910 \\
Agricultura*** & 13.345 & 19.800 & 26.348 & 29.918 & \\
Comércio Varejista & 69.663 & 111.608 & 156.452 & 218.406 & 255.115 \\
Comércio Atacadista & 9.742 & 11.467 & 14.802 & 17.578 & 19.494 \\
\hline *O quantitativo de estabelecimentos industriais abrange as indústrias metalúrgica, mecânica, química, têxtil e \\
calçados. \\
** Não tinha informação referente ao subsetor agricultura para o ano de 2013 \\
\hline
\end{tabular}

É possível considerar que nas últimas décadas várias áreas têm contribuído para inserir o Nordeste novamente no cenário da economia nacional. Dentre as áreas que vem apresentando maior dinamicidade tem-se o Complexo de Camaçari, o sub-médio São Francisco (Juazeiro/Petrolina) com agricultura irrigada, indústria têxtil no Ceará, entre outros casos que vem contribuindo na diversificação da economia, abrindo espaço para o aumento do setor de comércio e serviço, (ver mais detalhe em FIRMINO, 2016), que são chamados de "polos dinâmicos" e/ou "frentes de expansão" de acordo com as análises de Lima (1994, p. 56).

Destarte, é notório que a singularidade interiorana do Nordeste pode ser expresa de maneiras variadas: são as áreas de agricultura comercial, as regiões de especialização agrícola, indústrias desenvolvidas mediante investimentos de capitais locais, cooperativas organizadas por pequenos e médios agricultores e/ou empresários etc. Daí vê-se que "a heterogeneidade crescente vai consolidando dinâmicas particulares no interior dos diversos estados do Nordeste" (ARAÚJO, 1997, p. 33), apresentando uma região escassa no que concerne aos investimentos, mas possuindo uma riqueza ímpar essencial para a economia e desenvolvimento da mesma.

Diante destas breves observações fica claro que estudar mais a fundo e apresentar de forma séria a sub-região ora analisada - diga-se o Agreste - é de suma importância para apontar como se deu a gênese, a formação e o dinamismo do Nordeste brasileiro, estando para além da monocultura da cana e/ou da criação de gado no interior. Assim, é necessário enfrentar alguns problemas para que o processo de desenvolvimento em curso não seja interrompido. Logo, a densidade técnica, que é considerada baixa se comparada a outras regiões, é um desafio a ser encarado, visto o meio mecanizado a nível nacional continuar concentrado no eixo Sudeste-Sul, ou seja, na "Região Concentrada" do país (SANTOS e SILVEIRA, 2010), levando a assertiva que são os interesses hegemônicos, com destaque para os financeiros, os responsáveis por impor certas desigualdades entre as regiões brasileiras. Nesta referida região do país,

\footnotetext{
O meio técnico-científico-informacional se implantou sobre um meio mecanizado, portador de um denso sistema de relações, devido, em parte, a uma urbanização importante, ao padrão de consumo das empresas e das famílias, a uma vida comercial mais intensa. Em consequência, a distribuição da população e do trabalho em numerosos núcleos importantes é outro traço regional. (SANTOS e SILVEIRA, 2010, p. 269)
}

Sabendo-se da heterogeneidade apresentada pelo Nordeste, é importante ter-se melhor esclarecimento de cada sub-região, suas características sociais, políticas, culturais, econômicas etc., atentando para as ações capitalistas no decorrer dos anos e, consequentemente, perceber como o processo vigente de globalização está se dando no Nordeste, para em seguida fazer análises e interpretações não equivocadas da região, mostrando seu papel para o desenvolvimento econômico brasileiro como um todo. 


\section{AGRESTE: UMA SUB-REGIÃO DE TRANSIÇÃO NO NORDESTE DO BRASIL}

A sub-região chamada de Agreste no Nordeste do Brasil apresenta-se com características e condições climáticas favoráveis a uma maior diversidade no que concernem as atividades agrícolas, uso mais diversificado do solo e uma maior desconcentração da terra, diferenciando da tradicional atividade gado/cana-de-açúcar, podendo então, defini-la como uma sub-região de transição e de policultura (ANDRADE, 1998), com cultivo de feijão, milho, fumo, abacaxi, mandioca entre outas lavouras de subsistência. Assim, segundo Melo (1980, p. 33), o Agreste constitui-se no "maior espaço nordestino de uso diversificado da terra".

Pensando na diversificação apresentada pelo Agreste é possível apontar que a mesma é portadora de uma dinâmica singular, expressa por cidades de destaques que estão para além das capitais dos seus estados. Isto mostra que cidades interioranas se formaram, desenvolveram-se e hoje são referências a nível estadual, regional e quiçá nacional, com representatividade consolidada no que concerne aos aspectos, por exemplo, econômicos. Desta forma, a Figura 01 traz algumas das cidades de maiores destaques, apresentando o quantitativo de estabelecimentos segundo o grande setor da economia para as Microrregiões Agrestinas, segundo dados do IBGE (2012).

Figura 1. Microrregiões do Agreste: número de estabelecimentos - Grande Setor 2012

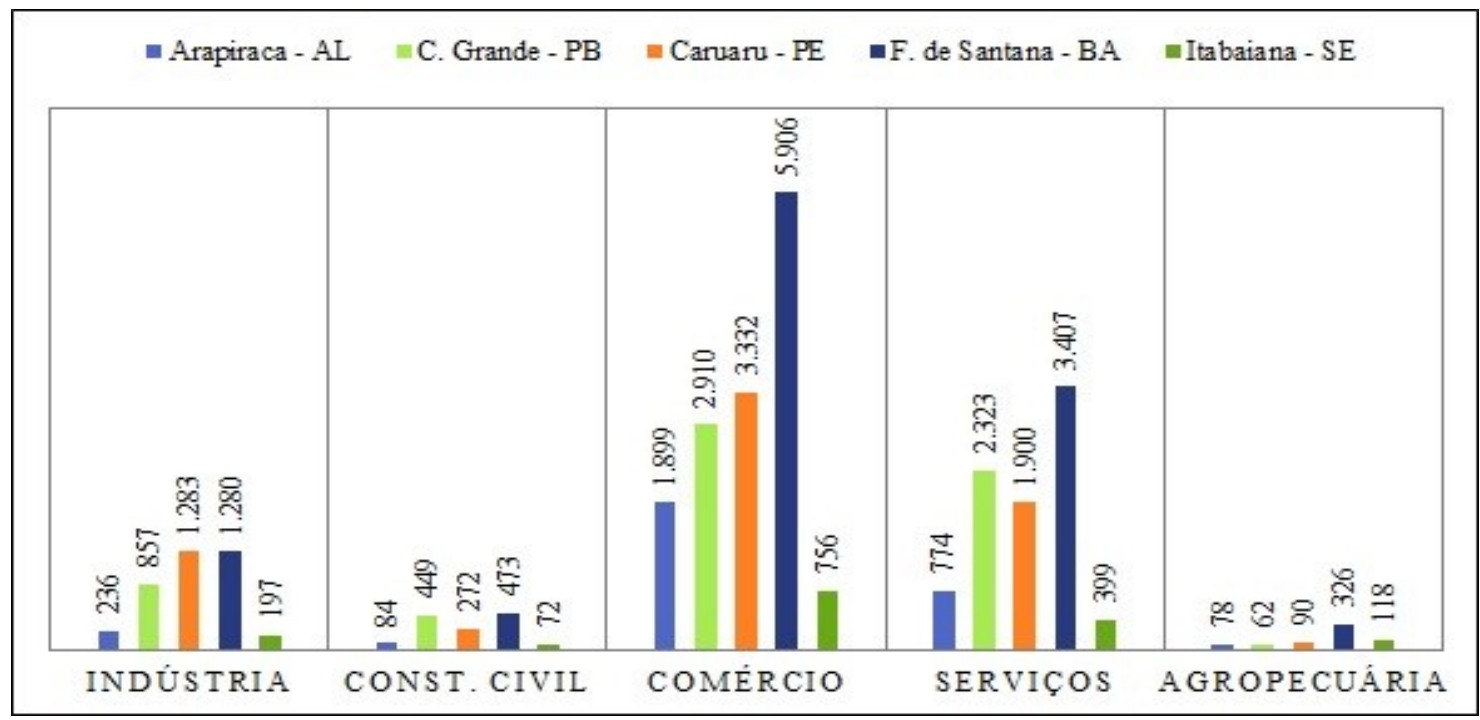

Fonte: http://www.mte.gov.br. RAIS Estabelecimento MES. Ano de 2012. Acesso em 12 de março de 2014 às 17h41min. Elaboração: FIRMINO, P. C. S

Mediante os dados do gráfico acima fica evidente a expressividade apresentada pelo Agreste. Suas atividades vão além daquelas utilizadas outrora com práticas apenas artesanais e agrícolas. Hoje é visível um dinamismo bastante arraigado por entre estas cidades, apresentando um comércio e setor de serviços que se destacam pela diversidade, força e centralidade que exercem em relação às cidades circunvizinhas.

Essa realidade presente nos dias atuais no Nordeste brasileiro, reflexo de um uso mais diversificado de suas terras, contribui significativamente para alavancar uma agricultura comercial que está para além daquela desenvolvida na Zona da Mata, por exemplo, renovando suas atividades e criando novos ramos no mercado local que passa a ser consolidado. É neste caminhar que Mamigonian (2009, p. 60) mostra que "começa a se acelerar no Nordeste a mudança da agricultura familiar de subsistencia, de baixa produtividade, para uma agricultura especializada, inserida no mercado e sujeita a melhores técnicas crescentes". 
Baseando-se no que expôs Mamigonian na citação do parágrafo anterior, vê-se que o investir nas atividades agrícolas especializadas, a criação de indústrias voltadas ao comércio interno é uma necessidade urgente para se ter um desenvolvimento regional e nacional. Assim, é preciso direcionar a produção para a população interna, suprindo primeiramente suas necessidades, diminuindo, consequentemente, as importações. Logo, ao criar um mercado nacional mais consolidado aumentará a responsabilidade do governo e das suas respectivas obrigações, tornando-se assim, “[...] mais complexas, uma vez que aumenta a circulação das mercadorias e a população se redistribui, porque em torno dos centros comerciais criam-se aglomerações urbanas" (RANGEL, 2012, p. 171).

O Agreste se apresenta como a sub-região que contrapõe economicamente as sub-regiões da concentração de terra e da monocultura, diga-se a Zona da Mata e o Sertão. Sua economia contribui significativamente para diversificar e dinamizar as relações existentes na região, levando-se também em conta as particularidades de cada estado, visto que, conforme Melo (1980, p. 38), "cada Agreste estadual constitui verticalmente parcela de uma grande unidade territorial definida como região agrária nordestina, mas horizontalmente figura como segmento territorial possuidor de funções muito relevantes dentro do Estado a que pertence".

Então, refletindo na diversidade e na dinâmica, presentes no Agreste, a Figura 02 traz um comparativo da evolução de admissões na indústria, comércio e serviços num período de 10 anos, compreendidos entre 2005 e 2015.

Figura 2. Agreste Nordestino: evolução de admissões - Grande Setor 2005/2015

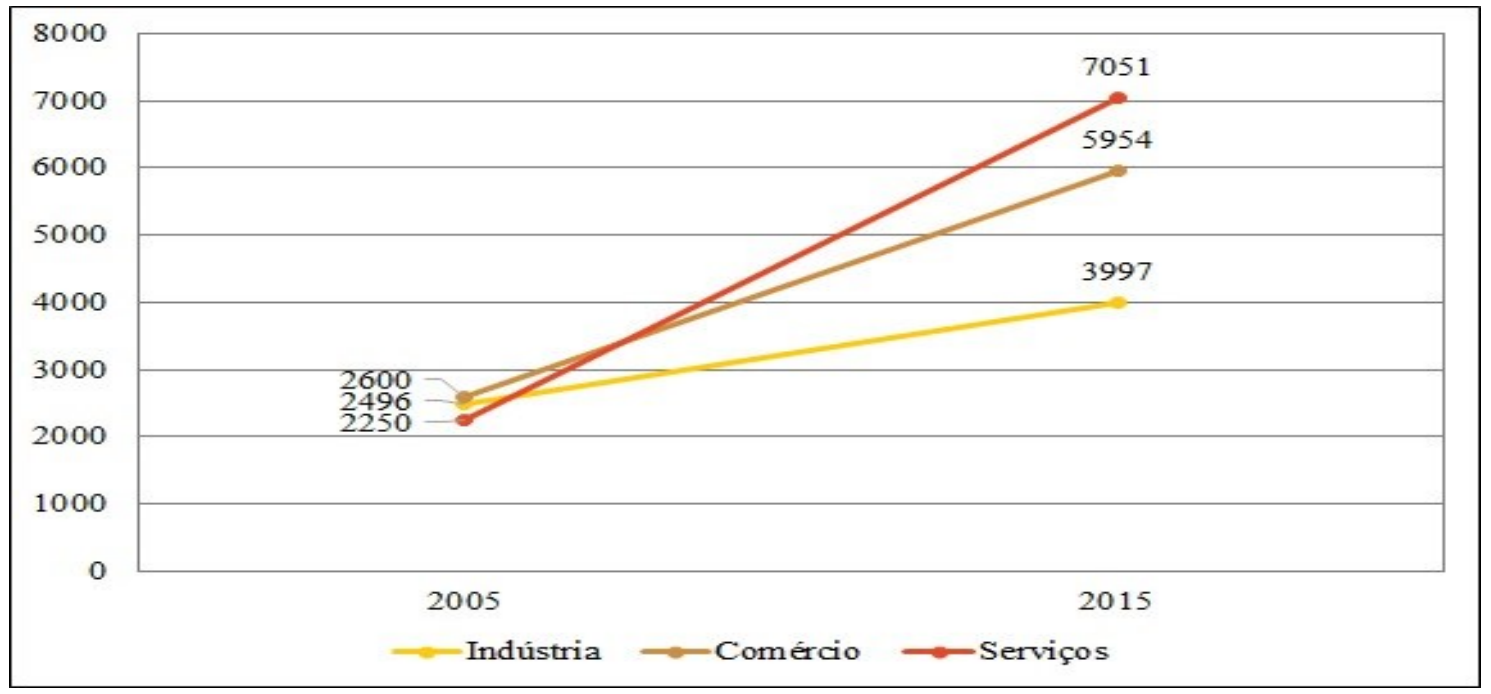

Fonte: MTE - Secretaria de Políticas Públicas de Emprego, Departamento de Emprego e Salário, Coordenação Geral de Estatísticas de Trabalho. In: http://bi.mte.gov.br/cagedestabelecimento/pages/consulta.xhtml\# Acessado em 10/05/2015 às 14h19min. Elaboração: FIRMINO, P. C. S.

O Agreste tem apresentado um aumento bastante significativo em relação ao comércio e, principalmente, no que se refere aos serviços, o que contribuiu para o desenvolvimento econômico agrestino. Grande parte das mudanças deve-se as iniciativas e investimos locais e regionais, com utilização de uma mão de obra também local. Assim, tem-se no Agreste o surgimento de um grande quantitativo de pequenos e médios comerciantes e empresários. Logo, para Mamigonian (1965, p. 72), partindo de "[...] negócios muito modestos, esses comerciantes vitoriaram-se graças ao espírito de iniciativa comum a todos eles".

Diante da quantidade de comerciantes e empresários que surgem nas cidades agrestinas, as atividades tendem a se diversificar sempre mais, desenvolvendo "atividades terciárias proporcionais às necessidades da população que a cerca, que se instala em sua área de 
influência" (ANDRADE, 1970, p. 61). Assim, atrai contingente mais amplo de pessoas dispostas a negociarem, seja para comprar, vender ou utilizar de algum tipo de serviço, refletindo desta forma na evolução socioeconômica das cidades do Agreste e, consequentemente, da região Nordeste.

É importante ressaltar que além da gama de negócios que surgem nas áreas urbanas têm-se aqueles com origens na zona rural de suas respectivas cidades, aumentando significativamente $o$ papel do agrestino na economia regional, colocando em evidência nos estudos regionais esta sub-região povoada tardiamente no decorrer do processo de ocupação do território brasileiro.

Discutir a importância e o papel desempenhado por algumas cidades que sobressaem no Agreste torna-se relevante para perceber como se dá todo o dinamismo existente no interior do Nordeste. Para tanto, evidenciar algumas cidades neste percurso torna-se fundamental na comprovação das assertivas até aqui apontadas. Sendo assim, não poderia deixar de citar as cidades de Campina Grande/PB, Caruaru/PE, Feira de Santana/BA, Itabaiana/SE e Arapiraca/AL. Cada uma com suas particularidades e com bastante expressividade para seus estados.

Para além das atividades agrícolas o processo de industrialização está aparecendo com mais destaque, contribuindo diretamente para a economia do Agreste. Tal processo teve sua gênese, em grande medida, atrelada a força de trabalho familiar, com uso de técnicas restritas, pouco capital investido e maquinário na maioria das vezes não moderno se comparado com indústrias de outras regiões que já surgem modernas e totalmente equipadas.

Diante disto, pode-se dizer que a indústria tinha muito as características de atividades mais artesanais, eram unidades que surgiam sem um planejamento antecipado, mas que no decorrer dos anos tornavam-se as mais importantes indústrias de suas cidades e estados, a exemplo do Grupo Coringa em Arapiraca/AL e Popular Alimentos que surgiu também em Arapiraca, mas que hoje se encontra instalada no Distrito Industrial de Pé Leve em Limoeiro de Anadia/AL; já em Sergipe têm-se as indústrias de carrocerias para caminhões na cidade de Itabaiana, como a Carroceria São Carlos (FIRMINO, 2016).

Desta forma, para entender a dinamicidade e toda transformação que as cidades do Agreste nordestino apresentam não se deve deixar de analisar a influência que os comerciantes das cidades têm no conjunto de medidas direcionadas para o desenvolvimento econômico de cada cidade, não esquecendo que ao lado da função industrial que ganha espaço nas últimas décadas tem-se destaque o comércio e os serviços.

\section{FEIRA LIVRE E AS CIDADES AGRESTINAS}

A estrutura econômica presente atualmente no Nordeste e, consequentemente, no território nacional, com uma diversidade de serviços, comércio e a própria indústria, tem raiz nas formas de comercialização que começou a se estruturar ainda no século $\mathrm{XV}$, sendo inicialmente voltada ao mercado exterior. É sabido que a economia em formação estava servindo aos anseios da Coroa Portuguesa, suprindo suas necessidades com os produtos escassos e/ou inexistentes em suas terras. Dentre estes se destaca num primeiro momento a cana-de-açúcar, visto ser o "principal produto de exportação do Brasil. [...]. Era o produto que contribuía para assegurar a formação do capitalismo português" (DIÉGUES JR., 2006, p. 16).

A economia nordestina, que durante séculos esteve relacionada diretamente com a cana e seus derivados, passou por diversas transformações ao longo do processo de formação e desenvolvimento econômico da sociedade brasileira, fortalecendo a relação de comercialização entre a Metrópole e a Colônia, intensificando assim, o desenvolvimento das trocas e um aumento na produção de valores, reflexo do aperfeiçoamento das técnicas existentes e do surgimento de outras. Pensando desta forma é possível afirmar que:

Quando a fase de pura subsistência é ultrapassada, torna-se necessário que os excedentes de cada grupo sejam trocados. É o momento da troca simples, do 
escambo. Mas este tipo primitivo de comércio não tem força para mudar a forma particular com que cada grupo valoriza o tempo e o espaço. É o comércio especulativo que traz mudanças, por criar uma nova relação social com a introdução da mercadoria e da moeda. (ARROYO, 2004, p. 51)

Pode-se dizer que a partir das relações estabelecidas pelos portugueses em terras brasileiras é que se têm os primeiros passos dados pelo que hoje se chama de feira livre, herança da comercialização estabelecida na colônia mediante suas experiências, sendo "estes modelos de mercados que foram trazidos para o Brasil no rastro do processo de colonização portuguesa no início do século XVI" (DANTAS, 2007, 60). É sabido que na região Nordeste um dos eventos de maior significado e importância foi a feira livre, como mencionado anteriormente, ainda continua sendo destaque e movimentando a economia de diversas cidades nordestinas, com maior expressividade para as localizadas na sub-região Agreste.

Destarte, vê-se que a vida econômica de muitas cidades nordestinas tem sua gênese baseada num mercado onde a comercialização e o negócio, eram feitos instantaneamente, vindo a caracterizar as chamadas feiras livres, sendo a primeira localizada em Capoame, norte do Recôncavo Baiano, por volta do século XVI e XVII (MOTT apud DANTAS, 2007).

Diversas feiras foram surgindo em terras nordestinas. Algumas delas surgiram a partir destas relações comerciais com o exterior, outras têm origem com a atividade pecuária que adentrava o interior do Nordeste, fazendo surgir esse tipo de comércio e povoados em virtude da criação e/ou deslocamento do gado, que segundo Pazera Jr. (2003, p. 37) "a Feira de Gado surgiu em função de uma atividade - a pecuária - amplamente favorecida pelas condições naturais favoráveis". Desta forma, apontar a cidade de Feira de Santana/BA torna-se um exemplo típico de cidade que surgiu no rastro traçado pelo gado ao adentrar o interior. Para Andrade (1979, p. 86), a cidade de "Feira de Santana, situada em uma zona de transição entre a área úmida e a semiárida, desenvolveu-se em torno de uma feira de gado, tornando-se rapidamente um dos principais núcleos urbanos do Estado".

Os primeiros núcleos de povoamento e as primeiras relações comerciais tiveram papel de destaque na estruturação das feiras livres, levando a percepção que ora elas contribuíam na formação das povoações e comércio, ora eram estes que as construíam. Era uma relação de complementariedade, que envolvia diversos setores e atores nas suas realizações. Então, elas foram eventos que contribuíram para a centralidade e dinâmica apresentada por cidades diversas, juntamente com outras melhorias, a exemplo dos transportes e das várias ligações entre litoral/interior e norte/sul, que contribuíram no processo de integração e interiorização da economia nordestina.

Mediante os avanços técnicos, científicos, informacionais e os novos processos econômicos, as feiras passam por mudanças que as fazem permanecerem vivas, coexistindo com as variadas formas de comercializações, exercendo papel importante economicamente. Assim, segundo Braudel (1998, p. 15), "se este mercado elementar, igual a si próprio, se mantém através dos séculos é certamente porque, em sua simplicidade robusta, é imbatível, dado o frescor dos gêneros perecíveis que fornece, trazidos diretamente das hortas e dos campos das cercanias".

Então, estudar esse tipo de mercado no Agreste, remete a entender os mais variados aspectos, percebendo que "têm as feiras, sobretudo no Agreste e no Sertão, onde domina uma atividade policultora, grande influência na economia local" (ANDRADE, 1974, p. 135), alcançando em muitos dos casos os estados circunvizinhos e outras regiões. Logo, observa-se que as mesmas no Agreste passam a "assumir um papel de destaque sendo, às vezes, difícil distinguir até que ponto a feira depende da cidade ou a cidade depende da feira" (PAZERA JR., 2003, p. 27).

Consideradas como atividade comercial de grandes proporções, as feiras têm contribuído significativamente para as cidades agrestinas, atraindo um número expressivo de pessoas não somente da zona urbana e rural de suas cidades, como de cidades vizinhas e de outros estados, movimentando a feira e o comércio, utilizando-se dos diversos tipos de serviços oferecidos por cidades com um maior poder de centralidade. Essa manifestação comercial, juntamente com a agricultura, contribuiu para a gênese de outras funções, diga-se a função industrial e/ou o surgimento de novos serviços. 
O surgimento de mercados muitas vezes especializados, como por exemplo, Shoppings-Centers, Supermercados etc., acarretam em desconforto para muitos dos atores que fazem parte da realização das feiras, visto que os representantes legais do poder público acabam por tomar decisões (como a mudança nos dias ou local de realização das feiras) que em sua maioria trazem benesses para um número limitado de atores que não fazem parte deste comércio tido como informal. No entanto, apesar dos desafios a serem enfrentados a feira ainda mantém seu poder frente aos novos eventos que surgem, podendo perceber que "se a vida econômica se acelera, à feira, relógio velho, não acompanha a nova aceleração; mas, se essa vida se desacelera, à feira recupera sua razão de ser" (BRAUDEL, 1998, p. 76).

Com a competitividade cada vez mais voraz imposta nos últimos decênios pelo processo de globalização vigente, tem-se um aumento gradativo pelos melhores territórios, acarretando num uso diferenciado por cada ator, sejam aqueles hegemônicos ou não-hegemônicos, destroçando, segundo Santos (2008), as solidariedades horizontais em benefícios de uma solidariedade cada vez mais verticalizada. Fica evidente uma oposição do espaço banal ao espaço econômico, ou como aponta Contel (2009, p. 131), "os tempos locais e regionais são cada vez mais substituídos pelos tempos nacionais ou globais. [...] As ações individuais e coletivas, portanto, perdem cada vez mais seu caráter orgânico com os lugares nos quais efetivamente se dão".

Desta forma, é nítido que as feiras livres, enquanto eventos inseridos diretamente no Circuito Inferior da economia urbana (SANTOS, [1979] 2008) participam da vida social, cultural e econômica das cidades, mesmo diante dos obstáculos que os(as) feirantes enfrentam para continuarem integrando essa manifestação (FIRMINO, 2016).

Atualmente os interesses capitalistas acabam por ofuscar e/ou concorrer com as feiras no que se refere à venda de alguns dos produtos tradicionalmente pertencentes a este mercado popular, diverso e dinâmico. Assim, pode-se dizer que os capitalistas buscam mercantilizar todos e quaisquer processos que giram nas mais diversas escalas econômicas, buscando sempre mais o acúmulo de capital (WALLERSTIN, 2001).

Nota-se que apesar dos produtos encontrados nas grandes redes de supermercados e atacados, que antes estavam restritos a feira, esta continua apresentando-se de forma diferenciada. É uma variedade de produtos, no frescor e na qualidade, formas de negociações com os clientes que é basicamente inexistente nas relações capitalistas, já que as feiras estão ligadas diretamente não só a economia, como a cultura do povo nordestino. Com isto, Dantas (2007, p. 23) mostra que o "estudo do comércio e, consequentemente de suas formas, nos possibilita enxergar as verdadeiras mudanças da sociedade, a evolução dos valores e as modificações na estrutura urbana". Portanto, é necessário estudar e conhecer mais de perto a realidade econômica não somente do Nordeste, como também das cidades agrestinas, que estão ligadas diretamente a formação econômica dos seus estados, da região e do território nacional.

\section{CONSIDERAÇÕES FINAIS}

Diante do exposto no presente artigo fica nítido que o Nordeste apresentou-se como região dinâmica economicamente nos primeiros séculos de colonização com a exploração das terras brasileiras a partir da cultura canavieira e das relações comerciais que estavam se estruturando. Entretanto, a estruturação econômica que era apresentada dava-se de forma diferenciada em cada uma das sub-regiões, com culturas e mão de obra diferenciada e adaptada a cada área, conforme analisado por Andrade (1998), sobressaindo dentre elas a sub-região Agreste.

Ao longo da formação e desenvolvimento econômico da região Nordeste diversos eventos contribuíram para que isto fosse possível, desde a cultura voltada para a cana, algodão, café até a diversidade da policultura apresentada pelo Agreste e suas respectivas cidades. Sendo assim, foi possível notar que esta sub-região apresenta-se com uma dinâmica e centralidade graças às diversas iniciativas que as colocam em evidência. São as iniciativas locais que fazem surgir empresas e 
indústrias voltadas a desenvolver a região, é a diversidade de atividades agrícolas espalhadas por entre as terras de policultura, um comércio que cresce e se expande cada vez mais, assim como a representatividade e importância que as feiras livres têm na vida econômica, social, cultural e política não só da sub-região como do Nordeste em sua totalidade. Para tanto, as cidades apontadas Caruaru/PE, Feira de Santana/BA, Arapiraca/AL, Itabaiana/SE e tantas outras - são exemplos das cidades que têm contribuído para inserir o Nordeste no cenário nacional no que se refere à vida econômica brasileira.

Por fim, não se pode deixar de mencionar que dentro de todo o conjunto econômico nordestino, existem as feiras, sobressaído desde o primeiro momento na vida econômica regional. Desta forma, em nenhum momento pode-se negar e/ou deixar de analisar como elas contribuíram e contribuem para a dinâmica e economia nordestinas, integrando uma parcela da população que não tem condições financeiras para serem inseridas em outros setores da economia.

\section{AGRADECIMENTOS}

À Fundação de Amparo à Pesquisa do Estado de São Paulo (FAPESP), pelo financiamento do projeto de pesquisa de mestrado, compreendido entre 2012 e 2015 (Processo $n^{\circ}$ : 2012/25256-5).

\section{REFERÊNCIAS}

ANDRADE, M. C. de. Espaço, polarização e desenvolvimento: a teoria dos pólos de desenvolvimento e a realidade nordestina. Recife: Centro Regional de Administração Municipal - CRAM, Editora Brasiliense, $2^{\mathrm{a}}$ ed. 1970.

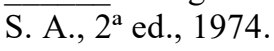

Geografia econômica do Nordeste: o espaço e a economia nordestina. São Paulo: Editora Atlas

. O Processo de ocupação do espaço regional do Nordeste. Recife: Ministério do Interior SUDENE, Superintendência Adjunta de Planejamento - Coordenação de Planejamento Regional, Divisão Política Especial. $2^{a}$ ed., 1979. 142p.

. Formação econômico-social e processos políticos no Nordeste brasileiro. In: MARANHÃO, S. (Org.) A questão Nordeste: estudos sobre formação histórica, desenvolvimento e processos políticos e ideológicos. Rio de Janeiro: Paz e Terra, pp. 31-39, 1984.

A Terra e o homem no Nordeste: contribuição ao estudo da questão agrária no Nordeste. São Paulo: Cortez, $6^{\text {a }}$ ed. 1998.

ARAÚJO, T. B. de. Herança de diferenciação e futuro de fragmentação. Dossiê Nordeste I. Estudos Avançados 11 (29), 1997.

ARROYO, M. Território, mercado e estado: uma convergência histórica. In: Geographia, Revista da Pós-Graduação em Geografia da Universidade Federal Fluminense/UFF. Rio de Janeiro: ano VI, $\mathrm{n}^{\mathrm{o}} 12$, dez. pp. 49-66, 2004.

BRAUDEL. F. Civilização Material, Economia e Capitalismo Séculos XV-XVIII. São Paulo: Martins Fontes, Tradução: Telma Costa, 1998.

CONTEL, F. B. Espaço geográfico, sistema bancário e a hipercapilaridade do crédito no Brasil. Caderno CRH, Salvador, v. 22, nº 55, Jan/Abr, pp. 119-134, 2009.

DANTAS, G. P. G. Feira livre de Macaíba/RN: um estudo das modificações na dinâmica socioespacial (1960/2006). 2007. 209p. Dissertação de Mestrado apresentada ao Programa de Pós-Graduação e Pesquisa em Geografia da Universidade Federal do Rio Grande do Norte/UFRN, Rio Grande do Norte, 2007.

DIÉGUES JR., M. O engenho de açúcar no Nordeste: documentação da vida rural. Maceió: EDUFAL, 2006. 92p.: il. - (Coleção Nordestina). 
Nordestina; 79).

População e açúcar no Nordeste do Brasil. Maceió: EDUFAL, 2a ed. 2012. 200p - (Coleção

FIRMINO, P. C. S. Arapiraca/AL e Itabaiana/SE - a feira livre como gênese e desenvolvimento de dois centros regionais do interior do Nordeste brasileiro. 2015, 306 f. Dissertação (Mestrado) Faculdade de Filosofia, Letras e Ciências Humanas/FFLCH, Universidade de São Paulo, São Paulo, 2016.

GRIMM, F. C. A. Trajetória epistemológica de Milton Santos: uma leitura a partir da centralidade da técnica, dos diálogos com a economia política e da cidadania como práxis. 2011. 307p. Tese de Doutorado apresentada ao Programa de Pós-Graduação em Geografia Humana da Faculdade de Filosofia Letras e Ciências Humana/FFLCH da Universidade de São Paulo/USP, São Paulo, 2011.

GUIMARÃES, A. P. Quatro séculos de latifúndio. Rio de Janeiro: Editora Paz e Terra S/A, 6 ed., 1989. 255p.

LÊNIN, V. I. O desenvolvimento do capitalismo na Rússia - o processo de formação do mercado interno para a grande indústria. Tradução de José Paulo Netto e revisão, com base no original russo, por Paulo Bezerra. São Paulo: Abril Cultural, 1982.

LIMA, P. Economia do Nordeste: tendências recentes das áreas dinâmicas. Revista Análise Econômica. Porto Alegre: Ano 12. no 21 e 22. Mar/Set, p. 55-73, 1994.

MAMIGONIAN, A. Estudo geográfico das indústrias de Blumenau. Revista Brasileira de Geografia, Rio de Janeiro: Secretaria de Planejamento e Coordenação da Presidência da República, Fundação Instituto Brasileiro de Geografia e Estatística - IBGE, v. 27, nº 3, pp. 389-482, 1965.

O Nordeste e o Sudeste na divisão regional do Brasil. Geografia Econômica - Anais de Geografia Econômica e Social. Grupo de Pesquisa/CNPq Formação Sócio-Espacial: Mundo, Brasil e Regiões. Universidade Federal de Santa Catarina. Florianópolis: Impressão no Departamento de Geociências, abril de 2009.

MELO, M. L. de. Os Agrestes: estudo dos espaços nordestino do sistema gado-policultura de uso de recursos. Recife: Ministério do Interior - SUDENE, Superintendência Adjunta de Planejamento Coordenação de Planejamento Regional, Divisão Política Especial - Estudos Regionais 4, 1980.

PAZERA JR. E. A feira de Itabaiana - PB: permanência e mudanças. 2003. 201p. Tese de Doutorado apresentada ao Programa de Pós-Graduação em Geografia Humana, da Faculdade de Filosofia Letras e Ciências Humana/FFLCH da Universidade de São Paulo/USP, São Paulo - SP, 2003.

RANGEL, I. Financiamento dos empreendimentos regionais. Anais do Seminário para o Desenvolvimento do Nordeste. Garanhuns: Confederação Nacional da Indústria, Serviço Social da Indústria - Divisão de Estudos e Planejamento, v. II, pp. 419-459, 1959.

Introdução ao desenvolvimento econômico brasileiro (1955). In Obras reunidas/Ignácio Rangel. v. I. Rio de Janeiro: Contraponto: Centro Internacional Celso Furtado de Políticas para o Desenvolvimento, 2012, 2v. (1.508p.). pp. 129-202.

SANTOS, M. O espaço dividido: os dois circuitos da economia urbana dos países desenvolvidos. São Paulo: Editora da Universidade de São Paulo/EDUSP, 2º ed., 1. reimpr. [1979] 2008 - (Coleção Milton Santos; 4). 440p.

Espaço e método. São Paulo: Editora da Universidade de São Paulo/EDUSP, 5. ed. [1985] 2008. (Coleção Milton Santos, 12). 118p.

SANTOS, M.; SILVEIRA, M. L. O Brasil: território e sociedade no início do século XXI. Rio de Janeiro: Record, $13^{\mathrm{a}}$ ed. 2010. 475p.

WALLERSTEIN, I. Capitalismo histórico e civilização capitalista. Tradução de Renato Aguiar e revisão de César BenJamin e Immanuel Wallerstein. Rio de Janeiro: Contraponto, 2001. 144p. 